for the consultation of original sources. Some of the methods described require elaborate technical equipment of a kind seldom found outside the largest institutions, but most of them are suitable for use in ordinary routine diagnostic laboratories. As a laboratory manual the present edition would be a valuable addition to the library of anyone in charge of a civil or military laboratory concerned with bacteriological diagnosis.

The book is well printed and produced. The binding is perhaps a little light for a volume intended for frequent reference at the bench. The combination of a particularly complete table of contents and a fairly full index makes it reasonably easy to find one's way about the book.

\section{THE HUMAN FOOT. Its Evolution, Physiology and Functional Disorders.}

By Dudley J. Morton. Pp.244. Oxford University Press. 1936. Price 15s. Od.

The author has presented his studies concerning the human foot in three parts. In Part I he discusses the evolutionary development including a description of amphibian, reptilian, mammalian and early primate feet and concludes that the human foot is a remarkable example of nature's use of engineering principles in the design of locomotor structures. Part II is devoted to consideration of the physiology of the human foot. In the maintenance of foot balance the author recognises the importance of both the muscles and ligaments and both of these factors are interrelated. The functional disorders of the human foot are considered in detail in Part III including the treatment of these conditions. Regarding the use of arch supports we thoroughly endorse the author's view that devices of this sort should only be used as a last resort and avoided as long as the functional capabilities of the feet have not been seriously impaired. The unnecessary employment of arch supports is undesirable as it tends to lead to progressive weakness.

This book presents the subject in an attractive manner and deals with it in a comprehensive way.

\section{ROSE AND CARLESS MANUAL OF SURGERY.}

By Cecil P. G. Wakeley and John B. Hunter. 15th Edition. 2 Vols. Pp.1618. Baillière, Tindall and Cox. London. 1937. Price 30s. 0d.

Since the publication of the first edition of this Manual of Surgery thirty-nine years ago, the book has been used by many generations of students: indeed, it has been one of the standard works on surgery in this country.

Considerable new matter has been incorporated in the present fifteenth edition. The chapter on Thoracic Surgery has been enlarged and rewritten; recent advances in the surgery of this region has made this necessary. A new chapter appears concerning Surgical Shock. The authors distinguish, possibly erroneously, between "primary"' and "secondary" shock. With regard to secondary shock it is stated that all observers are agreed that the constant feature is the depression of the blood pressure. It must be understood that a fall in the blood pressure only occurs when a considerable degree of shock is already present and therefore stress must be laid on the early features of the condition. We are surprised that the authors include under treatment, the intravenous administration of a 6 per cent. solution of gum arabic in normal saline. Consideration of the evidence regarding the value of this form of therapy will lead to its abandonment. We feel that greater detail might be given regarding the general management of patients suffering from this condition.

A chapter has been added on the Surgery of the Sympathetic System and a reasoned statement is given on the present position of this branch of surgery. The whole section dealing with the Surgery of the Central Nervous System has been rewritten and brought up to date.

In any text-book on Surgery the treatment of malignant disease must feature to a great extent and a section is devoted to the Use of Physical Agencies in Surgery. With regard to the treatment of cancer of the tongue the statement, that interstitial radium in the form of needles or seeds is the method most generally practised, must be questioned on account of the increasing application of teleradium in these cases. It is surprising that no mention is made regarding high voltage $X$-ray therapy in the treatment of cancer of the œsophagus.

The book is beautifully produced and this edition improves still further the already high standard of the work. It is to be recommended to all who desire a sound text-book on modern surgery.

\section{AIDS TO PSYCHIATRY.}

By W. S. Dawson, M.D., F.R.C.P., D.P.M. Pp. vii +320 . Baillière, Tindall and Cox. 1940. Price 4s. 6d.

The fact that this book has gone into a fourth edition proves its practical value. Clearly and concisely written by an expert, it gives the essential facts regarding psychiatry, for the student and general practitioner. We have also found it an ideal book for those lay persons, such as psychiatric social workers, and Honours students in psychology, whose work and studies necessitates an elementary knowledge of psychotic disorders.

Its weakness perhaps lies in the treatment of the psychoneuroses. For instance it says that "hysteria" flourishes in an atmosphere of excessive sympathy and attention (p. 106), whereas it is found on deeper investigation that it is often produced by the lack of sympathy. On the other hand electric therapy and massage which the author advocates, often does provide an atmosphere in which hysteria flourishes, since it reinforces the auto-suggestion in the patient's mind that he is suffering from an organic illness, not to speak of the pleasure derived from such treatment. 